\title{
Selection of Variety with High Performance Rose Apple (Syzygium jambos) Variety can be achieved with Morpho-Taxonomic Characterization
}

\author{
Anant Tamang ${ }^{1 *}$, Venkata Satish Kuchi ${ }^{1}$, B. C. Das ${ }^{2}$ and Soumik Ray ${ }^{3}$ \\ ${ }^{1}$ Department of Horticulture, ${ }^{3}$ Deparment of Economics and Agricultural Statistics, \\ MS Swaminathan School of Agriculture, Centurion University of Technology and \\ Management, R Sitapur, Gajapati, Odisha, 761211, India \\ ${ }^{2}$ Department of fruits and orchard management, Faculty of Horticulture, \\ BCKV, Mohanpur, Nadia, West Bengal, India \\ *Corresponding author
}

\section{A B S T R A C T}

Keywords

Rose apple,

Euclidean distance

matrix, Physical and

Biochemical

Parameters

Article Info

Accepted:

05 June 2020

Available Online:

10 July 2020
Rose apple (Syzygium jambos) is a popular fruit native to Southeast Asia. The blossoms contain hundreds of stamens and the fruits are crisp, juicy with distinct rose scent. The fruits are palatable with a moderate sweet taste. Rose apple contains low fibre level, appreciable level of vitamin $\mathrm{C}$, some level of acid, protein and ash content. In-situ characterization and preliminary evaluation are performed following Biodiversity International Tropical Fruit Descriptor. Total 6 numbers of accessions were taken under the study, the tree age varied from 18yrs to above 20yrs. Height and trunk girth varied from $8 \mathrm{~m}$ to above $12 \mathrm{~m}$ and $124.00 \mathrm{~cm}$ to $205.00 \mathrm{~cm}$ in studied accessions. Leaf characters in rose apple reveals lanceolate leaf blade shape, narrowly acuminate leaf apex, cuneate leaf base, opposite leaf orientation and arcuate leaf venation. Length of the leaf blade ranges from $19.21 \mathrm{~cm}$ to $25.04 \mathrm{~cm}$ and breadth varies from $4.08 \mathrm{~cm}$ to $6.54 \mathrm{~cm}$. Maximum fruit weight $(27.36 \mathrm{~g})$, seed weight $(12.11 \mathrm{~g})$ in ACC-3 and maximum number of seeds (2.4) in ACC-4 and ACC-3 were recorded. TSS ranged from $5.08^{\circ}$ Brix (ACC-4) to $6.08^{\circ}$ Brix (ACC-2). Average linkage technique clustering when applied on squared Euclidean distance matrix a total of 4 clusters were formed for plant physical parameters, fruit physical parameters and for fruit biochemical parameters.

\section{Introduction}

Syzygium jambos belonging to family Myrtaceae is a tree originated in Southeast Asia. Syzygium jambos is a medium sized tree upto 15 metres height with a low branching tendency. The edible fruit is guava shaped with thin, waxy skin which is extremely sensitive and has a pleasant floral aroma. They are eaten fresh or processed into jellies and jams, as they have high levels of pectin.

The tree is rich in tannins that are of some antimicrobial interest. The ash content of rose apple is $0.144 \%, 0.132 \%$ protein, $0.002 \%$ fibre, $0.66 \%$ fat and $4.10 \%$ total soluble solid. 
Rose apple is a kind of a fruit that can serve as a raw material in wine and fruit juice production (Bolarin et al., 2016).

Tuiwawa et al., (2013) has documented twenty species of Syzygium occurring in Vanuatu region and identification keys are provided for flowering and vegetative material. Morphological variation of a crop indicates the genetic diversity and effect from environment. Both environmental and genetic effects contribute to phenotypic variation within and among populations (Andrew et al., 2010). Exploration, conservation, utilization and correlation of different traits were studied under the topic genetic diversity of minor fruit in environmental condition of Tirana zones.

The study aimed to evaluate and characterize the available genotypes, to identify the genotypes with better characteristics for further propagation and uniformity plantation (Koka, 2012). Intensive work on germplasm collection, evaluation and improvement has been done on lasora, karonda and khejri which resulted in identification of some high yielding genotypes in these crops (Meghwal, 2018). To safeguard the existing diversity of this fruit and to achieve sustainable development based on use of available genetic wealth, promotion and conservation of this species is of immense importance.

\section{Materials and Methods}

Different agroclimatic zones of West Bengal were stratified depending on availability of fruit crop and on convenience of the study. The study has been carried out in Bidhan Chandra Krishi Viswavidyalaya, Mohanpur, Nadia, West Bengal during the years 20132015.

Data for this study has been generated through key informant survey and individual household survey from respondents by using semi-structured questionnaire. In-situ characterization and preliminary evaluation of under-utilised/minor fruit Rose apple (Syzygium sps.) are performed following Biodiversity International Tropical Fruit Descriptor.

The general information like age of the plant, behaviour of the plant was documented by making a questionnaire at the time of the survey. The genotypes were selected randomly with their varying age and location, which were further given accession numbers considering each accession as a treatment and replicating it for five times for all the quantitative parameters.

The analysis has been carried in three parts according to the variation in age of the plants and observations to be recorded. Under the observation for characterization, the plant physical parameters has been analyzed and so for preliminary evaluation fruit physical parameters and fruit biochemical parameters has been analyzed.

Multivariate analysis of characterization and evaluation parameters will be done following nearest neighbourhood method of hierarchical clusters analysis of squared Euclidean distance matrix on the basis of characters measured following Dillon and Goldstein (1984).

\section{Results and Discussion}

Total 6 numbers of accessions were taken under the study, 5 numbers of accessions belonged from institutional farm and 1 from Fatepur (Nadia district) Table 1. Branching pattern was observed to be irregular, semi circular crown shape and spreading type tree growth habit in all the accessions Table 2 . Leaf characters in rose apple revealed lanceolate leaflet blade shape, narrowly acuminate leaflet apex, cuneate leaflet base, 
opposite leaf orientation and arcuate leaf venation in all the observed accessions Table 3. Studies on morphology of Rose apple fruits has been documented in which spreading tree growth habit, long oblong-lanceolate leaves and almost spherical fruit characters has been reported (Mazumdar, 2004).

The proximity value of 114.51 between ACC2 and ACC-6 denoted the maximum similarity followed by 117.29 between ACC1 and ACC-4. The maximum value 6569.38 between ACC-3 and ACC-5 denoted the maximum dissimilarity for plant physical parameters Table 4.

Average linkage technique clustering when applied on squared Euclidean distance matrix a total of 4 clusters were formed for plant physical parameters. The data presented in the Table 5 and Fig. 1 showed that 1 to 2 clusters comprised of homogeneous types having similarity in characterization attributes. Cluster 3 and cluster 4 comprised of single member namely ACC-5 and ACC-3. ACC-2 and ACC- 6 formed the first cluster at the distance of 114.51 followed by 117.29 between ACC-1 and ACC-4 which formed the second cluster.

The value 0.72 between ACC-5 and ACC- 6 followed by 1.06 between ACC-4 and ACC- 6 denoted maximum similarities for fruit physical parameters. The maximum value 22.40 between ACC-1 and ACC-3 denoted minimum similarity Table 6 .

Average linkage technique clustering when applied on squared Euclidean distance matrix a total of 4 clusters were formed for fruit physical parameters. The data presented in the Table 7 and Fig. 2 shows that cluster 1 comprised of homogeneous types having similarity in characterization attributes. On the other hand 2 to 4 cluster comprised single member namely ACC-1, ACC-3 and ACC-2.
The first cluster comprised of ACC-5 and ACC-6 paired at the coefficient distance 0.72 followed by ACC-4 at the coefficient distance 1.34 .

ACC-5 and ACC-6 with minimum value 1.43 denoted the maximum similarity followed by 8.37 between ACC-4 and ACC-5. The maximum value 2145.46 between ACC-2 and ACC-3 denoted minimum accessions similarity for fruit bio-chemical parameters Table 8.

Haque et al., (2009) reported a study of five minor and three major fruits for nutritional and physico-chemical properties. The fruits were analyzed to determine the edible portion, $\mathrm{pH}$, titratable acidity, moisture, total soluble solid, reducing sugar, total sugar, crude fibre etc.

Average linkage technique clustering when applied on squared Euclidean distance matrix a total of 4 clusters were formed for fruit biochemical parameters. The data presented in the Table 9 and Fig. 3 shows that cluster 1 comprised of homogeneous types having similarity in characterization attributes.

On the other hand cluster 2 to 4 comprised single member namely ACC-3, ACC-1 and ACC-2. The first two accessions to pair were ACC-5 and ACC- 6 at the coefficient distance 1.43 followed by ACC-4 at the coefficient distance 9.91 respectively.

Documentation regarding great variabilities in the physico-chemical composition of Bael, Jack fruit and many other minor fruits has been reported by Singh (2001). Bal (2003) has documented on genetic diversity of some under-utilized fruit crops, namely Dhaeu and Karonda in Punjab to identify and conserve superior genotypes. Physico-chemical characters, maturity period and yield components had wide range of variability. 
Table.1 General experimental site details of Rose apple accession

\begin{tabular}{|c|c|c|c|c|}
\hline Accession no. & Name of owner & \multicolumn{2}{c|}{ Address } & \multicolumn{2}{c|}{ Site of characterization } \\
\hline ACC-1 & Hamida Banu & Fatepur, Jaguli (Nadia) & $22^{\circ} 56^{\prime} 17.40^{\prime \prime}$ & $088^{\circ} 35^{\prime} 16.87^{\prime \prime}$ \\
\hline ACC-2 & B.C.K.V. & Mandouri farm (Nadia) & $22^{\circ} 56^{\prime} 51.09^{\prime \prime}$ & $088^{\circ} 31^{\prime} 1.58^{\prime \prime}$ \\
\hline ACC-3 & B.C.K.V. & Mandouri farm (Nadia) & $22^{\circ} 56^{\prime} 51.09^{\prime \prime}$ & $088^{\circ} 31^{\prime} 1.58^{\prime \prime}$ \\
\hline ACC-4 & B.C.K.V. & Mandouri farm (Nadia) & $22^{\circ} 56^{\prime} 51.09^{\prime \prime}$ & $088^{\circ} 31^{\prime} 1.58^{\prime \prime}$ \\
\hline ACC-5 & B.C.K.V. & Mandouri farm (Nadia) & $22^{\circ} 56^{\prime} 51.09^{\prime \prime}$ & $088^{\circ} 31^{\prime} 1.58^{\prime \prime}$ \\
\hline ACC-6 & B.C.K.V. & Mandouri farm (Nadia) & $22^{\circ} 56^{\prime} 51.09^{\prime \prime}$ & $088^{\circ} 31^{\prime} 1.58^{\prime \prime}$ \\
\hline
\end{tabular}

Table.2 General tree characteristics of Rose apple accession

\begin{tabular}{|c|c|c|c|}
\hline Accession no. & Branching pattern & Tree growth habit & Crown shape \\
\hline ACC-1 & Irregular & Spreading & Semi circular \\
\hline ACC-2 & Irregular & Spreading & Semi circular \\
\hline ACC-3 & Irregular & Spreading & Semi circular \\
\hline ACC-4 & Irregular & Spreading & Semi circular \\
\hline ACC-5 & Irregular & Spreading & Semi circular \\
\hline ACC-6 & Irregular & Spreading & Semi circular \\
\hline
\end{tabular}

Table.3 Leaf characters of Rose apple accession

\begin{tabular}{|c|c|c|c|c|c|}
\hline Accession no. & $\begin{array}{c}\text { Leaf blade } \\
\text { shape }\end{array}$ & $\begin{array}{c}\text { Leaf apex } \\
\text { shape }\end{array}$ & $\begin{array}{c}\text { Leaf base } \\
\text { shape }\end{array}$ & $\begin{array}{c}\text { Leaf } \\
\text { Orientation }\end{array}$ & $\begin{array}{c}\text { Leaf } \\
\text { Venation }\end{array}$ \\
\hline $\mathbf{A C C}-\mathbf{1}$ & Lanceolate & $\begin{array}{c}\text { Narrowly } \\
\text { Acuminate }\end{array}$ & Cuneate & Opposite & Arcuate \\
\hline $\mathbf{A C C}-\mathbf{2}$ & Lanceolate & $\begin{array}{c}\text { Narrowly } \\
\text { Acuminate }\end{array}$ & Cuneate & Opposite & Arcuate \\
\hline $\mathbf{A C C}-\mathbf{3}$ & Lanceolate & $\begin{array}{c}\text { Narrowly } \\
\text { Acuminate }\end{array}$ & Cuneate & Opposite & Arcuate \\
\hline $\mathbf{A C C}-\mathbf{4}$ & Lanceolate & $\begin{array}{c}\text { Narrowly } \\
\text { Acuminate }\end{array}$ & Cuneate & Opposite & Arcuate \\
\hline $\mathbf{A C C}-5$ & Lanceolate & $\begin{array}{c}\text { Narrowly } \\
\text { Acuminate }\end{array}$ & Cuneate & Opposite & Arcuate \\
\hline $\mathbf{A C C}-6$ & Lanceolate & $\begin{array}{c}\text { Narrowly } \\
\text { Acuminate }\end{array}$ & Cuneate & Opposite & Arcuate \\
\hline
\end{tabular}


Table.4 Proximity Matrix for Rose apple plant physical attributes

\begin{tabular}{|c|c|c|c|c|c|}
\hline & \multicolumn{5}{|c|}{ Squared Euclidean Distance } \\
\hline & $1:$ ACC-1 & $2:$ ACC-2 & 3:ACC-3 & 4:ACC-4 & 5:ACC-5 \\
\hline 2:ACC-2 & 504.07 & & & & \\
\hline 3:ACC-3 & 4214.16 & 1833.53 & & & \\
\hline 4:ACC-4 & 117.29 & 150.45 & 3023.50 & & \\
\hline 5:ACC-5 & 283.66 & 1484.15 & 6569.38 & 716.80 & \\
\hline 6:ACC-6 & 1060.79 & 114.51 & 1049.45 & 514.98 & 2382.18 \\
\hline
\end{tabular}

This is a dissimilarity matrix

Table.5 Details of clusters for characterization variables using average linkage clustering methods on squared Euclidean distance matrix for Rose apple plant physical characters

\begin{tabular}{|c|c|}
\hline No. of clusters & Cluster members (Allowed distance co-efficient 117.29) \\
\hline $\mathbf{1}$ & Acc-2, Acc-6 \\
\hline $\mathbf{2}$ & Acc-1, Acc-4 \\
\hline $\mathbf{3}$ & Acc-5 \\
\hline $\mathbf{4}$ & Acc-3 \\
\hline
\end{tabular}

Table.6 Proximity matrix for Rose apple fruit physical attributes

\begin{tabular}{|l|c|c|c|c|c|}
\hline & \multicolumn{5}{|c|}{ Squared Eusclidean Distance } \\
\hline & $1:$ ACC-1 & 2 :ACC-2 & 3:ACC-3 & $4: A C C-4$ & 5:ACC-5 \\
\hline 2:ACC-2 & 4.45 & & & & \\
\hline 3:ACC-3 & 22.40 & 44.00 & & & \\
\hline 4:ACC-4 & 5.98 & 20.44 & 6.32 & & \\
\hline 5:ACC-5 & 4.28 & 15.02 & 7.72 & 1.62 & \\
\hline 6:ACC-6 & 2.56 & 13.06 & 10.16 & 1.06 & .72 \\
\hline
\end{tabular}

This is a dissimilarity matrix

Table.7 Details of clusters for characterization variables using average linkage clustering methods on squared Euclidean distance matrix for Rose apple fruit physical characters

\begin{tabular}{|c|c|}
\hline $\begin{array}{c}\text { No. of } \\
\text { clusters }\end{array}$ & $\begin{array}{c}\text { Cluster members } \\
\text { (Allowed distance co-efficient 1.34) }\end{array}$ \\
\hline $\mathbf{1}$ & Acc-5, Acc-6, Acc-4 \\
\hline $\mathbf{2}$ & Acc-1 \\
\hline $\mathbf{3}$ & Acc-3 \\
\hline $\mathbf{4}$ & Acc-2 \\
\hline
\end{tabular}


Table.8 Proximity matrix for Rose apple fruit biochemical attributes

\begin{tabular}{|c|c|c|c|c|c|}
\hline & \multicolumn{5}{|c|}{ Squared Euclidean Distance } \\
\cline { 2 - 6 } & $1:$ ACC-1 & $2:$ ACC-2 & 3:ACC-3 & 4:ACC-4 & 5:ACC-5 \\
\hline 2:ACC-2 & 15.37 & & & & \\
\hline 3:ACC-3 & 1817.39 & 2145.46 & & & \\
\hline 4:ACC-4 & 897.00 & 1123.01 & 177.00 & & \\
\hline 5:ACC-5 & 891.57 & 1125.42 & 164.02 & 8.37 & \\
\hline 6:ACC-6 & 890.75 & 1123.87 & 164.90 & 11.45 & 1.43 \\
\hline
\end{tabular}

This is a dissimilarity matrix

Table.9 Details of clusters for characterization variables using average linkage clustering methods on squared Euclidean distance matrix for Rose apple fruit bio-chemical characters

\begin{tabular}{|c|c|}
\hline $\begin{array}{c}\text { No. of } \\
\text { clusters }\end{array}$ & Cluster members (Allowed distance co-efficient 9.91) \\
\hline $\mathbf{1}$ & Acc-5, Acc-6, Acc-4 \\
\hline $\mathbf{2}$ & Acc-3 \\
\hline $\mathbf{3}$ & Acc-1 \\
\hline $\mathbf{4}$ & Acc- 2 \\
\hline
\end{tabular}

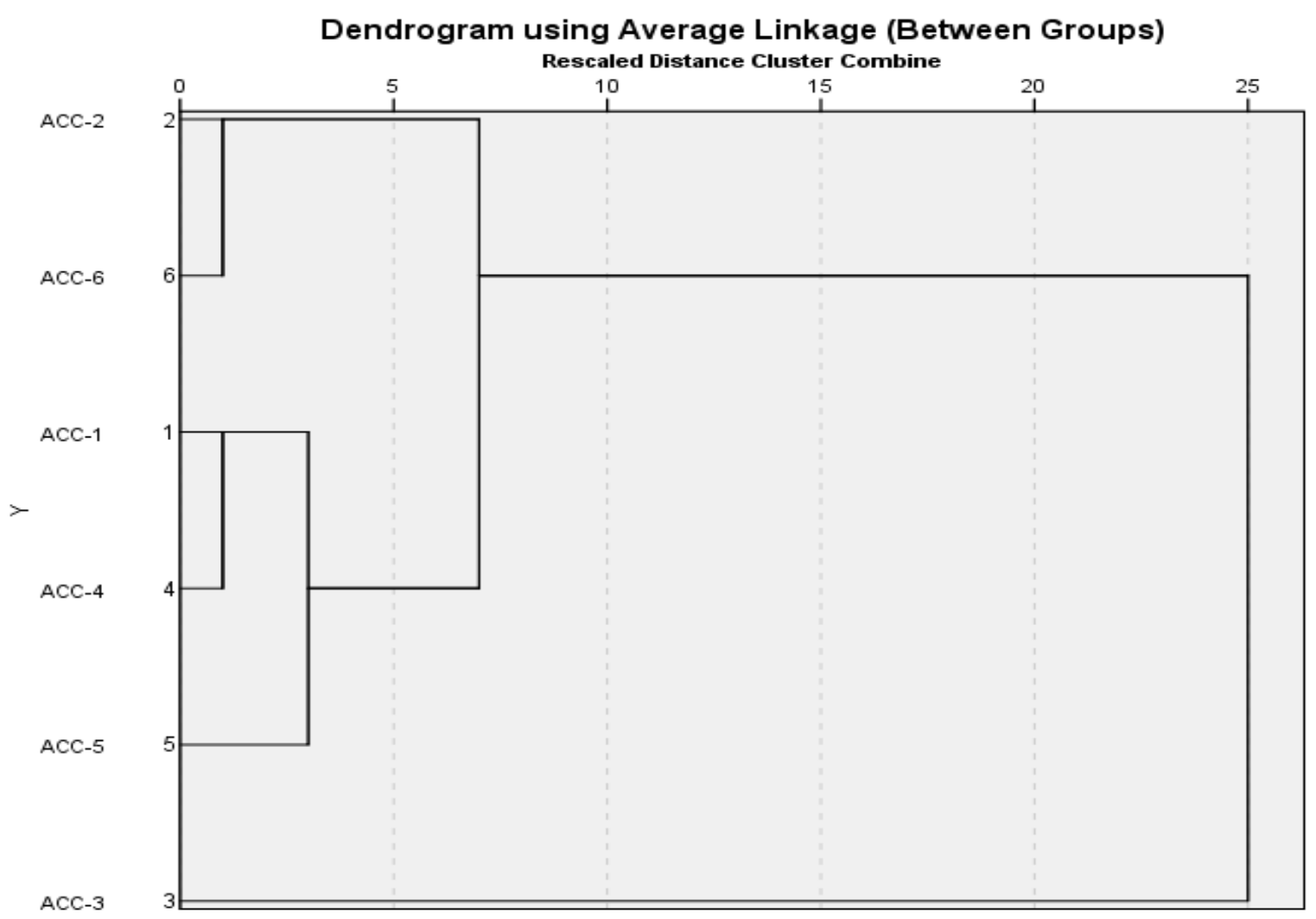

Fig.1 Dendrogram using average linkage hierarchical clustering of squared Euclidean distance matrix for Rose apple plant physical attributes 


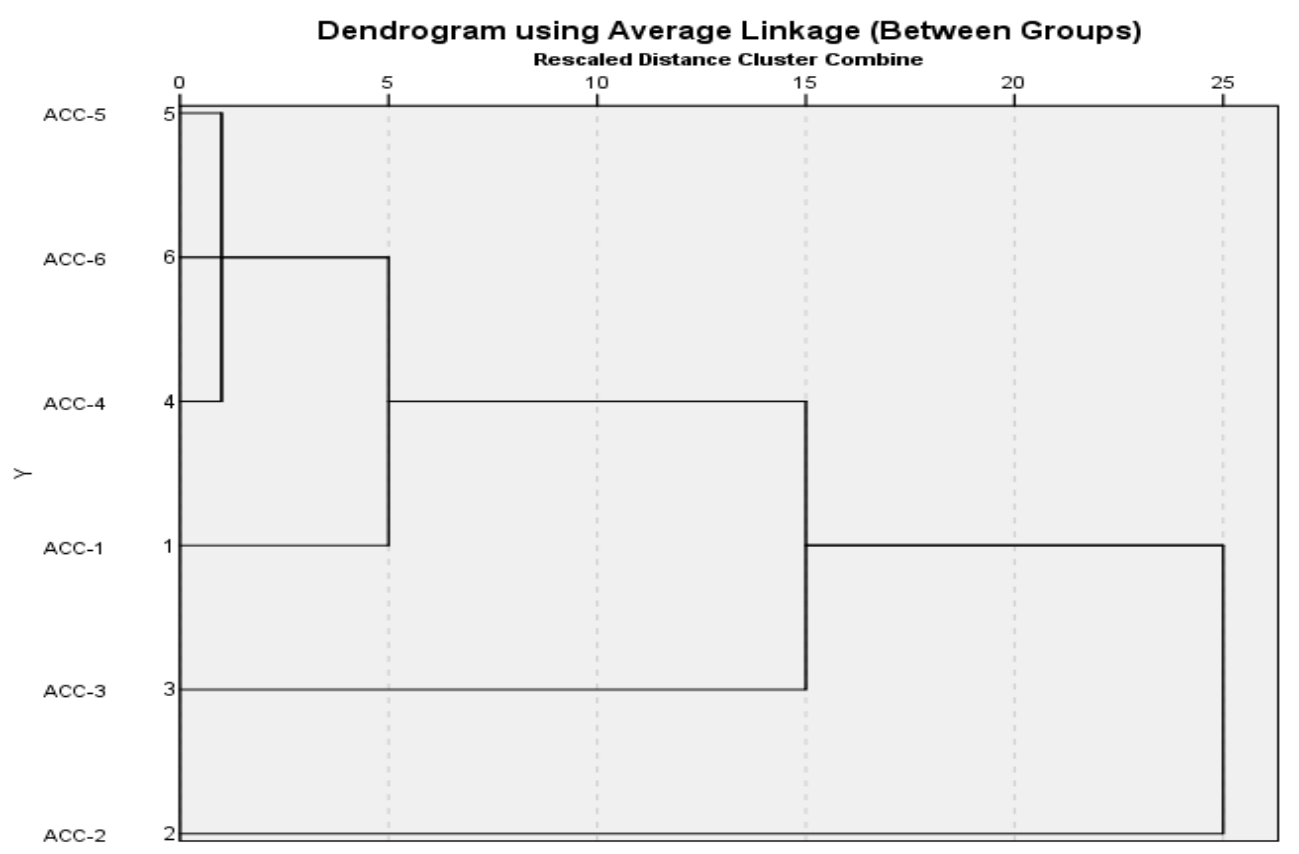

Fig.2 Dendrogram using average linkage hierarchical clustering of squared Euclidean distance matrix for Rose apple fruit physical characters

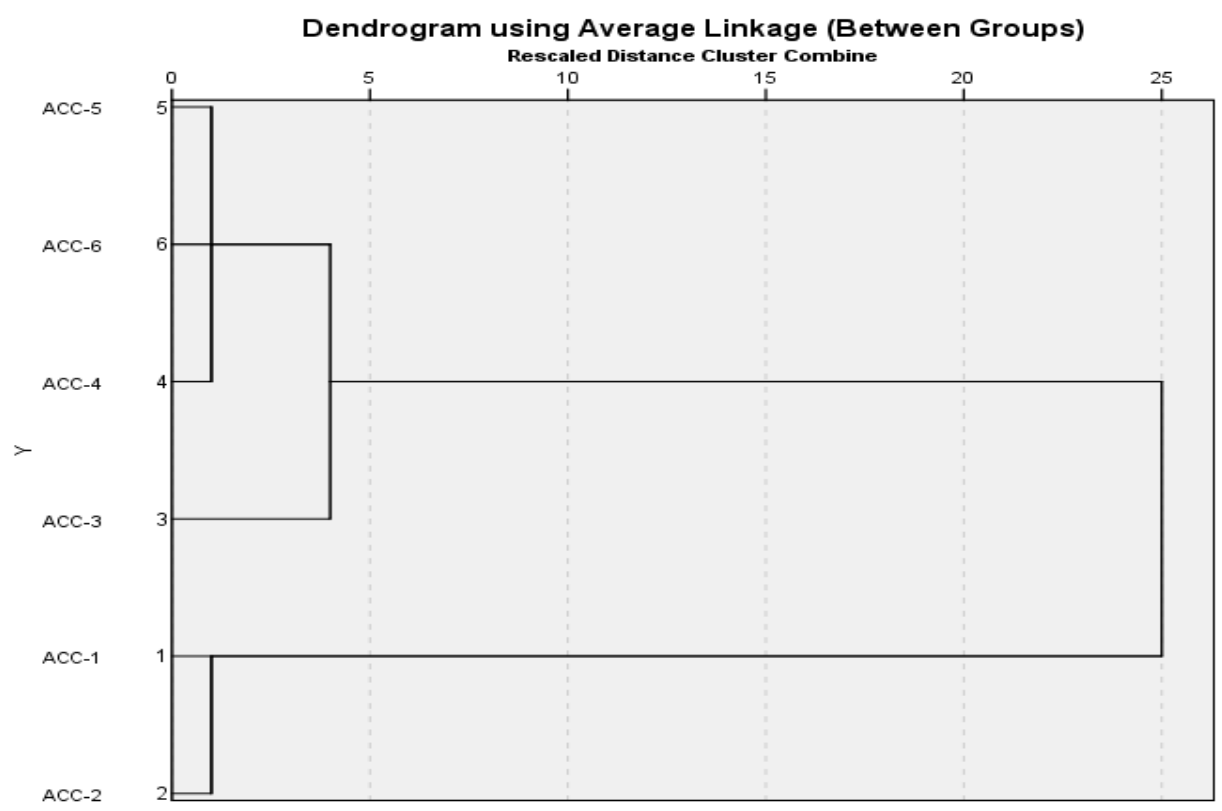

Fig.3 Dendrogram using average linkage hierarchical clustering of squared Euclidean distance matrix for Rose apple fruit bio-chemical characters

During the course of survey total 6 numbers of accessions were taken under the study, the tree age of rose apple accessions varied from 18 yrs to above $20 y r$ in different germplasm. Height and trunk girth varied from $8 \mathrm{~m}$ to above $12 \mathrm{~m}$ and $124.00 \mathrm{~cm}$ to $205.00 \mathrm{~cm}$ girth.
Branching pattern was observed to be irregular, semi-circular crown shape and spreading type tree growth habit in all the accessions. Leaf characters in rose apple reveals lanceolate leaf blade shape, narrowly acuminate leaf apex, cuneate leaf base, 
opposite leaf orientation and arcuate leaf venation. Length of the leaf blade ranges from $19.21 \mathrm{~cm}$ to $25.04 \mathrm{~cm}$ and breadth varies from $4.08 \mathrm{~cm}$ to $6.54 \mathrm{~cm}$. Maximum fruit length was recorded in ACC-1 $(3.32 \mathrm{~cm})$ and breadth of $3.32 \mathrm{~cm}$ in ACC-4. Maximum fruit weight $(27.36 \mathrm{~g})$, seed weight (12.11 g) in ACC-3 and maximum number of seeds (2.4) in ACC4 and ACC-3 were recorded.

TSS ranged from $5.08^{\circ}$ Brix (ACC-4) to $6.08^{\circ}$ Brix (ACC-2). Maximum total sugar 5.81 $\mathrm{mg} / 100$ gm (ACC-6), pulp reducing sugar $17.85 \mathrm{mg} / 100 \mathrm{gm}$ (ACC-3), acidity 0.581 $\mathrm{mg} / 100 \mathrm{gm}$ (ACC-5) and Vit.C $71.00 \mathrm{mg} / 100$ gm (ACC-3) has been recorded. Average linkage technique clustering when applied on squared Euclidean distance matrix a total of 4 clusters were formed for plant physical parameters, fruit physical parameters and for fruit biochemical parameters.

\section{References}

Andrew, R.L., Wallis, I.R., Harwood, C.E. and Foley, W.J. (2010). Genetic and environmental contributions to variation and population divergence in a broad spectrum foliar defence of Eucalyptus tricarpa. Annual Botany. 105:707-717.

Bal, J.S. (2003). Genetic resources of underutilized fruits in Punjab subtropics. Acta Horticulture. 623:325-331.
Bolarin, F.M., Olotu, F.B. and Onyemeize, U.C. (2016). Rose apple fruit: it prospects for juice and wine production. European Journal of Educational and Development Psychology, 4(2):25-32.

Haque, M.N., Saha, B.K., Karim, M.R. and Bhuiyan, M.N.H. (2009). Evaluation of nutritional and physic-chemical properties of several selected fruits in Bangladesh. Bangladesh Journal of Scientific and Industrial Research. 44(3):353-358.

Koka, T. (2012). Genetic diversity of minor fruit in environmental condition. Journal of International

Environmental Application \& Science. 7(4):829-833.

Mazumdar, B.C. (2004). Minor fruit crops of India: Tropical and subtropical, Daya publishing house. 95-98.

Meghwal, P. R. (2018). Collection, evaluation and improvement of some underutilized

fruits in hot Indian desert. Indian Journal of Arid Horticulture. 13 (1-2): 49-64

Singh, I.S. (2001). Minor fruits and their uses. Indian Journal of Horticulture. 58(1/2): 178-182.

Tuiwawa, S.H., Craven, L.A., Sam, C. and Crisp, M.D. (2013). The genus Syzygium (Myrtaceae) in Vanuatu. Blumea. 58:53-67.

\section{How to cite this article:}

Anant Tamang, Venkata Satish Kuchi, B. C. Das and Soumik Ray. 2020. Selection of Variety with High Performance Rose Apple (Syzygium jambos) Variety can be Achieved with MorphoTaxonomic Characterization. Int.J.Curr.Microbiol.App.Sci. 9(07): 329-336. doi: https://doi.org/10.20546/ijcmas.2020.907.035 